\title{
Identification of antioxidant properties of Morus rubra
}

\begin{abstract}
Lately, natural antioxidants are on demand globally for anti-aging and health purposes. Red mulberry has been discovered to have antioxidant properties and it is edible by man. In this study, antioxidant properties of different parts of Morus rubra (red mulberry) which were harvested from Malaysia were investigated. The target study parts of Morus plant were unripe fruits, ripe fruits, leaves, petiole, and stem. DPPH assay and $\mathrm{H}_{2} \mathrm{O}_{2}$ assay were used to study the antioxidants properties of red mulberry in vitro. The results of this study had shown that leaves extract has the highest antioxidants properties with inhibition values of $86.69 \pm 0.954 \%$ in DPPH assay and $32.94 \pm 1.516 \%$ in $\mathrm{H}_{2} \mathrm{O}_{2}$ assay. On the other hand, stem extract of mulberry showed the lowest antioxidants properties among all with inhibition values of $7.18 \pm 1.201 \%$ in DPPH assay and $3.97 \pm 2.728 \%$ in $\mathrm{H}_{2} \mathrm{O}_{2}$ assay. The result indicated that the DPPH radical scavenging properties of different parts of mulberry are as the order of leaves, petiole, ripe fruit, unripe fruit and stem from high to low. On the other hand, the same order was discovered for $\mathrm{H}_{2} \mathrm{O}_{2}$ radical scavenging activity. Further studies can be undertaken to understand how the dose of each extract of mulberry affect their antioxidant properties. Hence, the IC50 value of different parts of mulberry can be studied.
\end{abstract}

Volume 12 Issue I - 2019

\author{
Lim WM,Teo SS \\ Department of Applied Sciences, UCSI University, Malaysia
}

Correspondence: Teo SS, Department of Applied Sciences, UCSI University, No. I, Jalan Menara Gading, UCSI Heights, 56000 Cheras, Kuala Lumpur,WP, Kuala Lumpur, Malaysia, Tel +603-91018880,Email teoss@ucsiuniversity.edu.my

Received: January 22, 2019 | Published: February 13, 2019

Keywords: antioxidants, morus rubra, in vitro, reactive oxygen species, hydrogen peroxide, Alzheimer's disease

Abbreviations: ROS, reactive oxygen species; $\mathrm{O}^{2-}$, superoxide; $\mathrm{H}_{2} \mathrm{O}_{2}$, hydrogen peroxide; $\mathrm{NO}$, nitric oxide

\section{Introduction}

The human body composed of a structure system of natural enzymatic and non-enzymatic antioxidant defenses which counteract the adverse effects of free radicals and other oxidants. Free radicals are causing a massive number of diseases including cancer, cardiovascular disease, neural disorders, Alzheimer's disease mild cognitive impairment, Parkinson's disease; alcohol induced liver disease, ulcerative colitis, aging and atherosclerosis. ${ }^{1}$ An antioxidant is a molecule capable of slowing or preventing the oxidation of other molecules.

The most common reactive oxygen species (ROS) include superoxide $\left(\mathrm{O}^{2-}\right)$ anion, hydrogen peroxide $\left(\mathrm{H}_{2} \mathrm{O}_{2}\right)$, peroxyl ( $\left.\mathrm{ROO}-\right)$ radicals, and reactive hydroxyl $(\mathrm{OH})$ radicals. The nitrogenderived free radicals are nitric oxide $(\mathrm{NO})$ and peroxynitrite anion (ONOO). When the generation of ROS induced by various stimuli in the organism exceeds the antioxidant capacity of the organism, it will lead to a variety of pathophysiological processes. The harmful intervention of ROS in normal metabolic processes leading to pathologic changes is a consequence of their interaction with various biological compounds inside and outside cells. ${ }^{2}$

Consuming antioxidant rich food brings health benefit which provides protection from free radical damage that causes aging and many degenerative diseases like macular degeneration. In the last few decades, berries are being marketed greatly with its antioxidant properties. The most common berries such as blueberries, cranberries as well as acai berries that are claimed to be super food are all grown or only grown well in foreign countries mainly European countries. One of the berries that can be grown greatly in Malaysia is the red mulberry.
The mulberry belongs to the Morus genus of the Moraceae family. There are 24 species of Morus, with at least 100 known varieties. ${ }^{3}$ Mulberry, as a powerhouse of nutrient, contains fibers, sugars, carbohydrates, proteins, lipids, minerals, and vitamins. Apart of its antioxidant properties that help in preventing aging, Boone ${ }^{4}$ reported that mulberries also help in improving digestive health, blood circulation, immunity and liver health, building bone tissue, controlling blood sugar level, promoting brain health. Other than that, consuming mulberry can reduce cancer risk and helps curing anemia. ${ }^{5,6}$ Lee et al. ${ }^{7}$ suggested mulberry as an anti-inflammatory agent. The parts of mulberry tree have long been used as medicine in China. ${ }^{8}$ Thus, in this study the parts of red mulberry were used to study the antioxidant properties.

The objective of this research is to determine the antioxidant properties of different parts of red mulberry tree (M. rubra) which includes unripe and ripe fruits, leaves, petiole and stem.

\section{Methodology}

\section{Sample preparation}

All collected plant materials were grinded using grinder. Briefly, $2 \pm 0.01 \mathrm{~g}$ fresh weight of each grounded sample was extracted with $5 \mathrm{~mL}$ of $75 \%$ aqueous methanol containing $0.1 \%$ formic acid followed by $15 \mathrm{~min}$ sonication. All treated samples were then centrifuged for $10 \mathrm{~min}$ at $2700 \mathrm{~g}$, and the supernatant was collected. Another $5 \mathrm{~mL}$ of $75 \%$ aqueous methanol containing $0.1 \%$ formic acid was added to the pellet, and the extraction procedure was repeated two times. All three supernatants were combined and adjusted to a final volume of $15 \mathrm{~mL}$ Unripe fruits extracts, ripe fruits extracts, leaves extracts, petiole extracts and stem extracts were collected in falcon tubes and were labelled with sample 1 until 5 accordingly. Prepared extracts were stored at $20^{\circ} \mathrm{C}$ until analysis. 


\section{In vitra antioxidant activity}

\section{Scavenging Capacity Towards DPPH}

The DPPH scavenging activity of the extract was measured as described previously. ${ }^{9}$ An aliquot $(200 \mu \mathrm{L})$ of the extract from 3.6 was added to $1 \mathrm{ml}$ of a methanolic DPPH solution $(500 \mu \mathrm{M})$. The mixture was then vortexed vigorously and left for $30 \mathrm{~min}$ at room temperature in the dark. There was a colour changes observed in the mixture from deep violet to pale yellow. After 30min of reaction, absorbance of extract was measured at $517 \mathrm{~nm}$ using UV-vis spectrophotometer and compared to a blank control that contained the solvent and DPPH reagent. This protocol was done to all 5 extracts of mulberry plant. Negative control was prepared by replacing the extract with distilled water while BHT was used in positive control.

\section{Scavenging capacity towards hydrogen peroxide $\left(\mathrm{H}_{2} \mathrm{O}_{2}\right)$}

The $\mathrm{H}_{2} \mathrm{O}_{2}$ scavenging activity of extract was determined by the method as described previously. ${ }^{10}$ The extracts from 3.6 were dissolved in $3.4 \mathrm{~mL}$ of $0.1 \mathrm{M}$ phosphate buffer $(\mathrm{pH} 7.4)$ and mixed with $600 \mu \mathrm{L}$ of $\mathrm{H}_{2} \mathrm{O}_{2}(43 \mathrm{mM})$. The absorbance value of the reaction mixture was recorded at $230 \mathrm{~nm}$ using UV-vis spectrophotometer. This protocol was done to all 5 extracts of mulberry plant. Negative control was prepared by replacing the extract with distilled water while BHT was used in positive control.

\section{Data analysis}

The experiment of in vitro anitoxidants sceening of each extracts were performed in triplicate. All data were used to calculate the inhibition values on DPPH assay and $\mathrm{H}_{2} \mathrm{O}_{2}$ assay. The inhibition values of both DPPH and $\mathrm{H}_{2} \mathrm{O}_{2}(\%)$ of the mulberry extracts were calculated using this formula:

$$
I \%=\frac{\mathrm{A} 0-\mathrm{A} 1}{A 0} \times 100
$$

Where,

I \% = inhibition value,

$\mathrm{A} 0=$ the absorbance of control reaction,

$\mathrm{A} 1=$ the absorbance in presence of test or standard sample.

Inhibition values of all 5 extracts were recorded as means \pm standard deviation of triplicates.

\section{Results and discussion}

In this experiment, methanolic extraction was used to prepare plant material extracts. Arabshahi-Delouee and Urooj ${ }^{11}$ had studied about the antioxidant properties of various solvent extracts of mulberry and has discovered that methanolic extract can get the highest amount of total phenolics from compound and get the most potent antioxidant in all the assays used. ${ }^{11}$ The colour of ripe fruit extract was appeared in light pink while unripe fruit extract was appeared in pale yellow. There was a decreasing in intensity of green colour observed from leaves extract, petiole extract to stem extract. Green colour solution is a result of pigmentation of chlorophyll from plant. The intensity green colour appeared is influenced by the concentration of chlorophyll present. ${ }^{12}$ All methanolic extracts had shown clear solution.

\section{In vitro antioxidant activity}

DPPH free radicals were decolorize by the reaction of antioxidant compound and they further reacts with DPPH radical produce the purple colour and its convert in to 1-1- diphenyl-2-picryl hydrazine have the colourless property, and was measured at $517 \mathrm{~nm}$. The absorbance values of each extracts from the experiment were used to calculate the inhibition value. Table 1 showed the calculated inhibition values of DPPH assay for unripe fruits, ripe fruits, leaves, petiole and stem.

Table I Inhibition value of DPPH assay

\begin{tabular}{llll}
\hline S. no & Extracts & Inhibition (\%) & P-value \\
\hline S1 & Unripe Fruits & $21.64 \pm 1.104$ & \\
S2 & Ripe Fruits & $32.82 \pm 1.322$ & \\
S3 & Leaves & $86.69 \pm 0.954$ & \\
S4 & Petiole & $33.58 \pm 0.683$ & \\
S5 & Stem & $7.18 \pm 1.201$ & \\
BHT & BHT & $81 \pm 0.211$ &
\end{tabular}

According to the data collected from the experiment, the inhibition value of DPPH assay towards the mulberry extracts were calculated and were performed in table form. There was an indication of a statistically significant difference between the different type of extracts and the inhibition values to DPPH assay as seen from Table 1 as the p-value obtained was 0.000 which was lesser than 0.05 . From Table 1, S3 showed the highest inhibition towards DPPH assay following by S4, S2, S1 and S5. This concludes that leaves extracts have the highest ability to scavenge towards DPPH radicals following by petiole, ripe fruits, unripe fruits and stem. The inhibition value of leaves extract was $86.69 \pm 0.954 \%$, which is also higher than BHT. On the other hand, stem extract has been discovered to have least ability to scavenge DPPH radical with an inhibition value of $7.18 \pm 1.201 \%$.

The absorbance values of each extracts from the experiment were used to calculate the inhibition value. Table 2 showed the calculated inhibition values of $\mathrm{H}_{2} \mathrm{O}_{2}$ assay for unripe fruits, ripe fruits, leaves, petiole and stem.

Table 2 Inhibition value of $\mathrm{H}_{2} \mathrm{O}_{2}$ assay

\begin{tabular}{llll}
\hline S. no & Extracts & Inhibition (\%) & P-value \\
\hline S1 & Unripe Fruits & $6.83 \pm 0.177$ & 0 \\
S2 & Ripe Fruits & $20.3 \pm 0.341$ & \\
S3 & Leaves & $32.94 \pm 1.516$ & \\
S4 & Petiole & $24.54 \pm 0.057$ & \\
S5 & Stem & $3.97 \pm 2.728$ & \\
\hline
\end{tabular}

From the studies, the data collected have been used to calculate the inhibition value of $\mathrm{H}_{2} \mathrm{O}_{2}$ assay towards the mulberry extracts. The analysed data were performed in table form. There was an indication of a statistically significant difference between the different type of extracts and the inhibition values to $\mathrm{H}_{2} \mathrm{O}_{2}$ assay as seen from Table 2 as the p-value obtained was 0.000 which was lesser than 0.05 . From Table 2, S3 showed the highest inhibition towards $\mathrm{H}_{2} \mathrm{O}_{2}$ assay following by S4, S2, S1 and S5 This conclude that leaves extracts have the highest ability to scavenge towards $\mathrm{H}_{2} \mathrm{O}_{2}$ radicals following by petiole, ripe fruits, unripe fruits and stem. The inhibition value of leaves extract was $32.94 \pm 1.516 \%$, which was lower than BHT $(49.34 \%)$. On the other hand, stem extract has been discovered to have least ability to scavenge $\mathrm{H}_{2} \mathrm{O}_{2}$ radical with an inhibition value of $3.97 \pm 2.728 \%$. 
The results of this study have shown that leaves extract has the highest antioxidants properties while stem extract shows the lowest antioxidants properties among all. This is mainly because of the leaf of mulberry contains high amount of total phenolic and flavonoid contents. Thabti et al. ${ }^{13}$ had found out that the total phenolic and total flavonoid contents of red mulberry leaves were $994.3 \mathrm{mg}$ gallic acid equivalents $/ 100 \mathrm{~g}$ of dry matter and $789.7 \mathrm{mg}$ rutin equivalents $/ 100 \mathrm{~g}$ of dry matter, respectively.

From the result, leaves extracts show higher antioxidant activity compares to fruits extract. Similar result was reported that the leaves of Morus species had been discovering to have higher antioxidant activity compare to the fruits in both DPPH assay and FRAP assay. ${ }^{14}$ The studied Morus species were black mulberry (Morus nigra), white mulberry (Morus alba) and red mulberry (M. rubra). According to the study of Dimitrova et al., ${ }^{15}$ the in vitro antioxidant activities of M. rubra leaves was $3.2 \pm 0.1 \mathrm{mM} \mathrm{TE} / \mathrm{g}$ fw while $M$. rubra fruit was $1.0 \pm 0.2 \mathrm{mM} \mathrm{TE} / \mathrm{g}$ fw using DPPH assay meanwhile the result also showed that the antioxidant activities of Morus plant was influenced by its total phenolic content. The total phenolic content of $M$. rubra leaves and fruits were $2.2 \pm 0.2 \mathrm{mg} \mathrm{GAE} / \mathrm{g}$ fw and $0.9 \pm 0.1 \mathrm{mg} \mathrm{GAE} / \mathrm{g}$ fw respectively as reported. ${ }^{14}$ Moreover, Chon et al. also reported that methanol extract of mulberry leaves $(71.4 \pm 2.4 \mathrm{mg} \mathrm{FAE} / \mathrm{kg} \mathrm{dw})$ was found to have higher phenolic content than fruit $(11.2 \pm 0.3 \mathrm{mg} \mathrm{FAE} /$ $\mathrm{kgdw})$.

Furthermore, leaves extract of M. rubra also shown higher antioxidant activity than stem extract of M. rubra. The result is in accordance to garden cress plant (Lepidium sativum) and chaff-flower (Achyranthes aspera) which were reported by Malar et al. and Vijay and Rakesh respectively. Malar and friends reported that the free radial scavenging activity of garden cress leave was $10.21 \pm 0.7 \%$ while stem was $2.69 \pm 0.5 \%$ at $100 \mu \mathrm{g} / \mathrm{ml}$ of extracts. Vijay and Dr. Rakesh also found out that leaves of chaff-flower showed higher DPPH scavenging activity which was $24.95 \pm 0.78 \%$ compare to the stem $(15.86 \pm 0.43 \%)$.

On the other hand, the result also summarized that ripe fruit of mulberry has higher antioxidant activity in both assay than unripe fruit which is close to the result of pepino (Solanum muricatum) fruit. Ripe pepino fruit was reported to exhibit higher value of antioxidant activity in DPPH assay than unripe fruit with EC 50 values of $2.20 \mathrm{mg} /$ $\mathrm{mL}$ and $3.75 \mathrm{mg} / \mathrm{mL}$ respectiveity. ${ }^{15}$ Sudha et al. ${ }^{15}$ also suggested that the observed difference between the antioxidant activity, polyphenol and flavonoid contents of ripe and unripe pepino fruit could be due to biotransformation of glycosylated polyphenol to aglycosylated polyphenol during the maturation stage.

The antioxidant activity of mulberry leave shown higher than BHT in DPPH assay which is in correspondence with Lee et al. ${ }^{16}$ It was reported that antioxidant activity of plants is higher than that of synthetic antioxidants. ${ }^{16}$

However, there are limited studies with sufficient data to support the results for petiole extract of mulberry.

\section{Conclusion}

Synthetic phenolic antioxidants such as butylated hydroxytoluene (BHT) and butylated hydroxyanisole (BHA) have been commonly uses as antioxidants in food industry, cosmetics, and therapeutic industry. However, during elevated temperature, both BHT and BHA become high volatility and instability. Hence, natural antioxidants would be promising alternative for synthetic antioxidants. They are low cost, highly compatible with dietary intake and no harmful effects inside the human body. Plant has been discovered to contain many antioxidant compounds naturally. Attempts have been made to study the antioxidant potential of fruits. ${ }^{17}$ According to Halvorsen et al., fruit berries contain the best dietary sources of bioactive compounds (BAC).

In this study, antioxidant properties of extracts from different parts of Morus rubra were studied. This study demonstrated that the DPPH radical scavenging properties of different parts of Morus plant are as the order of leaves, petiole, ripe fruit, unripe fruit and stem from high to low. Moreover, the same order was discovered for $\mathrm{H}_{2} \mathrm{O}_{2}$ radical scavenging activity. In summary, leaves of M. rubra exhibited highest antioxidant properties while stem of $M$. rubra had least antioxidant properties comparing to the rest. On the other hand, the antioxidant activity of the leaves extract was higher than the standard antioxidant, BHT, with DPPH assays. However, BHT had higher inhibition activity with $\mathrm{H}_{2} \mathrm{O}_{2}$ assay than all mulberry extracts.

\section{Acknowledgments}

None.

\section{Conflicts of interest}

Author declares no conflicts of interest towards this article.

\section{References}

1. Alam M, Bristi N, Rafiquzzaman M. Review on in vivo and in vitro methods evaluation of antioxidant activity. Saudi Pharmaceutical Journal. $2013 ; 21(2): 143-152$.

2. Yang J, Guo J, Yuan J. In vitro antioxidant properties of rutin. LWTFood Science and Technolog. 2008;41(6):1060-1066.

3. Orhan E, Ercisli S. Genetic relationships between selected Turkish mulberry genotypes (Morus spp) based on RAPD markers. Genet Mol Res. 2010;9(4):2176-2183.

4. Boone L. Powerful plant-based superfoods. Fair Winds Press. 2013;4143.

5. Eo HJ, Park JH, Park GH, et al. Anti-inflammatory and anti-cancer activity of mulberry (Morus alba L.) root bark. BMC Complement Altern Med. 2014;14(1):200.

6. Hartvig K. Healing berries. Duncan Baird Publishers. 2016;23.

7. Lee CY, Cheng HM, Sim SM. Mulberry leaves protect rat tissues from immobilization stress-induced inflammation. Biofactors. 2007;31(1):2533.

8. Zhishen J, Mengcheng T, Jianming W. The determination of flavonoid contents in mulberry and their scavenging effects on superoxide radicals. Food Chemistry. 1999;64 (4):555-559.

9. Tailor C, Goyal A. Antioxidant Activity by DPPH Radical Scavenging Method of Ageratum conyzoides Linn. Leaves. American Journal of Ethnomedicine. 2014;1(4):244-249.

10. Ruch RJ, Cheng SJ, Klaunig JE. Prevention of cytotoxicity and inhibition of intercellular communication by antioxidant catechins isolated from Chinese green tea. Carcinogenesis. 1989;10(6):1003-1008.

11. Arabshahi-Delouee S, Urooj A. Antioxidant properties of various solvent extracts of mulberry (Morus indica L.) leaves. Food Chemistry. 2007;102(4):1233-1240.

12. Shibghatallah M, Khotimah S, Suhandono S, et al. Measuring leaf chlorophyll concentration from its color: A way in monitoring environment change to plantations. AIP Conference Proceedings. 2013;1554(1):210 213. 
13. Thabti I, Marzougui N, Elfalleh W. et al. Antioxidant composition and antioxidant activity of white (Morus alba L.), black (Morus nigra L.) and red (Morus rubra L.) mulberry leaves. Acta Botanica Gallica. 2011;158 (2):205-214.

14. Dimitrova M, Petkova N, Denev P, et al. Carbohydrate Composition and Antioxidant Activity of Certain Morus Species. International Journal of Pharmacognosy and Phytochemical Research. 2015;7(3):621-627.
15. Sudha G, Priya MS, Shree RB, et al. Antioxidant Activity of Ripe and Unripe Pepino Fruit (Solanum muricatumAiton). J Food Sci. 2012;77(11):C1131-C1135.

16. Lee SE, Hwang HJ, Ha JS, et al. Screening of medicinal plant extracts for antioxidant activity. Life Sci. 2003;73(2):167-179.

17. Wang H, Cao G, Prior R. Total Antioxidant Capacity of Fruits. Journal of Agricultural and Food Chemistry. 1996;44(3):701-705. 